\title{
The Effectiveness of Communication Efforts in Raising Family Awareness about the Seriousness of Children Using Screens and Electronic Devices
}

\author{
Dr. Ahmed Mostafa Kamel \\ Assistant professor- Al Falah university- Dubai
}

\begin{abstract}
This research is based on descriptive research aimed at analyzing the effectiveness of communication efforts related to the controls of children's use of electronic devices in educating parents about the seriousness of using such devices, and the extent to which regulations and instructions for the rational use of such devices have been adopted and applied, the research relies on a sample survey method for data access, the information required to be studied and analyzed through a questionnaire was applied to a sample of (450) individuals. The research has reached many results, the most important of which is the high rate of exposure of parents to communication efforts to raise awareness from multiple sources and various means, especially the International Network for Personal Information and Communication, and high awareness among parents of the dangers of misuse of those devices, with the low rate of compliance with the rules of regulation and rational use, and the existence of significant differences between fathers and mothers with regard to allowing their children to use those devices.
\end{abstract}

Keywords: Screens and Electronic Devices - Communication Efforts - Education and Family Care Children - Awareness.

\section{Introduction}

Modern communication technologies have provided many means of attraction for different age groups in order to participate and interact in a way that increased their immersion with those means, and the different media and content they carry.

Electronic devices such as smartphones, game consoles, and electronic tablets are becoming increasingly popular, and it reached many sectors and categories of users, until it becomes part of the daily system of family life in general, and children in particular in various Arab and Western societies, which increased the use of these devices and stuck their users and accompanied them even to their bedrooms, as a scientific study showed that $(97 \%)$ of American teens have at least one electronic device in their bedroom. With the spread of easy-to-use electronic tablets, children have become, according to many data, a target audience representing a new and fertile consumer market for marketers, one year after the advent of IPad, specifically in (2011), (10\%) of children under two years are using a tablet and a smartphone, and after about three years, the figure quadrupled, where in France in (2015), a study found that $(58 \%)$ of children under the age of two used a tablet or smart phone. The development of children's use of these electronic devices has evolved until the production of cell phones for children starting from the age of four, this has led many countries to reject these products, including France, which opposed the order and demanded the protection of children.

Many studies have shown the health, mental, and physical effects of excessive use of the Internet and electronic communication and entertainment devices for children, and the health and mental repercussions continue to unfold continuously, as these studies pointed to the occurrence of so-called addiction to the use of these devices, this was associated with higher rates of depression, anxiety and stress, studies have also pointed to a relationship between the use of these devices and irregular sleep and a sense of stability, in addition to violent behavior, or aggressive behavior, hyperactivity, obesity, impaired body and vision, and low school performance, as well as changing heart rate, and other side effects.

These negative effects on children's health as a result of the use of these devices led to the issuance of strict statements by the American Society of Pediatrics to ensure that children under the age of two years are not allowed to watch TV, or the presence of electronic devices in their rooms, and the duration of the watch for children over the age of two years for not more than two hours a day, and the American Academy of Pediatrics also urged parents of 
children between the ages of two and five not to allow their children to use communication and digital displays of all kinds for more than an hour a day, noting that the appropriate duration for children aged 6 to 12 years is a maximum of two hours per day, taking into account the selection and review of the content of what children watch.

There is no doubt that the restrictions and health controls set by many scientific and health institutions as well as the American Academy of Pediatrics must reach all target audiences, especially parents, and good targeting of the audience may not always mean high awareness of the issue, perhaps awareness is not associated with compliance with regulations and instructions for controlling and rationalizing children's use of electronic screens and devices, noting that many families sought to purchase these devices and provided them to their children, for the purposes of entertainment and recreation, and sometimes the skills and education development, or education, which strengthened the relationship between the child and devices and electronic screens with the consent of parents, regardless of their level of knowledge of the seriousness of their children use those devices.

The research has crystallized in exploring and describing the relationship between the effectiveness of communication efforts in raising the awareness of the Arab family about the danger of children using electronic screens.

The research was significant in exploring and describing the relationship between the effectiveness of communication efforts in raising the awareness of the Arab family about the danger of children using electronic screens, and their impact on preventing or rationalizing their children's use of those devices, where the responsibility of parents in the follow-up of the child and the provisions of censorship, and on the electronic devices he uses in various stages of the age, from lactation to pre-adolescence, or late childhood, which lasts up to twelve years, where the adolescence begins, in which the family's control of children are somewhat reduced, and show whether there are differences between parents in allowing their children to use these devices.

The importance of this research is that there is rarely available studies that examine the effectiveness of communication efforts and track their impact, regardless of its source whether governmental or non-governmental organizations, or media of various kinds, especially in matters related to the controls of healthy and educational life, despite the multiplicity of health, education and media interested in this type of issues.

The research was concerned with tracking the effectiveness of communication efforts in educating parents about the rules of their children's use of electronic devices, and if the effectiveness of these efforts has extended beyond the stage of drawing attention and building awareness, in order to achieve the response of the audience and change their behaviors towards the use of their children to these devices, with the verification of certain hypotheses concerning awareness and discipline among parents.

The importance of the research is that it belongs to the fields of communication and educational studies, where it presents its findings and recommendations to the various bodies that are responsible for effective awareness and aiming to provide a safe and healthy environment for children, and to ensure the importance of parents awareness and their commitment to maintaining the health of future generations.

\section{Previous studies}

The study of Cain \& Gradisar (2010): This study was concerned with investigating many variables that concerned the relationship of children with electronic devices and their vulnerability to those devices, the study found that the use of these devices affected the total sleep time of children and adolescents of school age, this was confirmed by a study conducted in Norway by (M Hysing et, all: 2015) on teenagers aged 16-19, the study showed the association of sleep variables with using these devices, with increased risk of short sleep duration, and long time when you start sleeping, which means a correlation between the duration of sleep and the use of electronic devices.

The negative effects of these devices on children are already confirmed in the results of many important studies, they are not all of the medical or health effects as presented by the study of (blessed Zarqouni, 2018) which is titled Child and Technology Between Uses and 
Influences where she pointed to the excessive use of smart electronic devices by children, especially children between the ages of 8 to 12, and she pointed to the damage caused by these devices, which are social and psychological effects besides physical health damage, the study recommended that parents take appropriate precautions towards their children using these devices, which has been repeated in many previous studies, and the seriousness of those results is the need to examine the extent of the development of the phenomenon of intensive use of children to these devices and electronic screens where the study of (Saqabi: 2015) which was conducted in Morocco on a sample of (200) parents concluded that the child now prefer to stay with electronic devices to sit with the family, as for the prevalence of this phenomenon in the society where the study was conducted by (almazme, 2013) in which he pointed to the high rates of children's use of modern technology in the UAE, where it showed that $(41 \%)$ of children use modern technology at a rate of four to eight hours a day, While (29\%) of them use an average of two to four hours a day, which is very high figures call us to look at another corner of the subject and verify the quality and impact of communication efforts aimed at addressing this phenomenon.

\section{Discussion of the Previous Studies}

Many studies deal with the different effects of children's use of electronic devices and its psychological effects on children's behavior and social life, some of these studies have monitored the rates of use of these devices by children, while many studies have been observed to engage in health and medical effects. this has affected many of these studies and it is almost certain that there are many negative effects on children due to overuse of electronic devices.

It was also noted that some studies have gone beyond the stage of proving the negative damages of uncontrolled use by children of these devices to examine the reasons for the children's attraction to these devices, and the relationship of the social environment of the child in promoting that attraction and dealing with these devices for a long time, The previous study pointed to the importance of the researcher's tendency towards the research problem from an educational communication perspective, where there are targeted communication efforts to raise awareness of the need to control children's use of these devices, which are communication activities targeting parents, despite the proliferation of these devices and high rates of use, and parents continue to buy these devices in their various forms, this indicates the need for research and studies dealing with these topics from different psychological, social and economic perspectives to the legal aspects where discussing the extent of criminalization of excessive use and bring charges to parents if necessary.

\section{Methodology}

This study belongs to descriptive studies aimed at describing and analyzing the problem, and how a particular situation occurs, in order to obtain sufficient information and draw useful results and indications, where the research effort deals with awareness-raising efforts on the controls of children's use of electronic devices and the extent to which parents control their children's use of these devices starting of the responsibility of parents for the health of their children, the research is based on the survey methodology of a sample in order to access the data, and the information required to study it, and analysis by relying on a questionnaire applied to the study sample, the questionnaire was presented to a list of arbitrators to ascertain the suitability of the categories of analysis, the questionnaire was revised after some revisions to be finalized.

The step of determining the study population is one of the most important difficulties faced by the researcher during the study, due to the breadth of the vocabulary that has the characteristics to be studied, this problem was dealt with after consulting the consultants and specialists, where the study population was identified by parents with children up to the age of late childhood, the research sample was identified by (450) members from the parents with children aged (2-12) years from Arab families residing in the United Arab Emirates, this is a number that enables the researcher to check the relationship between two variables during the hypothesis validity test.

The UAE has been identified as citizens and residents of the UAE belonging to a relatively high financial level, which enables them to provide electronic devices to their children if they wish to acquire them, diversity in the 
representation of parents in the study sample was taken into account, where the number of mothers was (159) individuals, representing $(54.9 \%)$, and the number of fathers (141) individuals, representing (45.1\%), with a commitment to equitable distribution among citizens of six Arab countries residing on the territory of the United Arab Emirates as follows (United Arab Emirates, Egypt, Jordan, Palestine, Syria, and Sudan) with (75) individuals per country, which contributes to enhancing the benefit of the study results in different countries of the region, and the time frame for this study was extended from January to April 2019.

\section{Objective}

The problem of the present study has been formulated in the following questions:

1. What is the extent of exposure to awareness-raising communication efforts to control the children's use of screens and electronic devices?

2. What are the sources of communication efforts and communication awareness messages that have been exposed to?

3. To what extent are parents sure of the risk of irrational use of electronic devices and screens?

4. Do parents have awareness of the controls to use these devices?

5. To what extent do parents apply health procedures and controls regarding their children's exposure to these devices?

\section{Hypotheses of the study}

- There are statistically significant differences between parents regarding the extent of awareness of the seriousness of their children using screens and electronic devices.

- There are statistically significant differences between parents with regard to their adherence to their children's use of screens and electronic devices in exchange for child satisfaction

- There are statistically significant correlation differences between parents' follow-up of traditional media and their perception of the seriousness of children using screens and electronic devices.
- There are statistically significant differences between parents' follow-up on social networking sites and their perception of the seriousness of children using screens and electronic devices.

\section{Results of the study}

\section{First: Basic data of the respondents}

The results showed the basic data of the respondents where $(47.1 \%)$ in the age group 20 to less than 35 years, (49\%) in the age group 35 to less than 50 years, $(3.9 \%)$ from 50 years to more, as for the distribution of the study sample by educational level, it was as follows: $(8.3 \%)$ of those with intermediate qualifications, $25.8 \%$ of those with higher qualifications, $56.2 \%$ of graduate students, $9.7 \%$ of post graduate students.

\section{Second: Results of the field study}

Figure (1): the extent of exposure to awareness-raising communication efforts to control the use of children screens and electronic devices

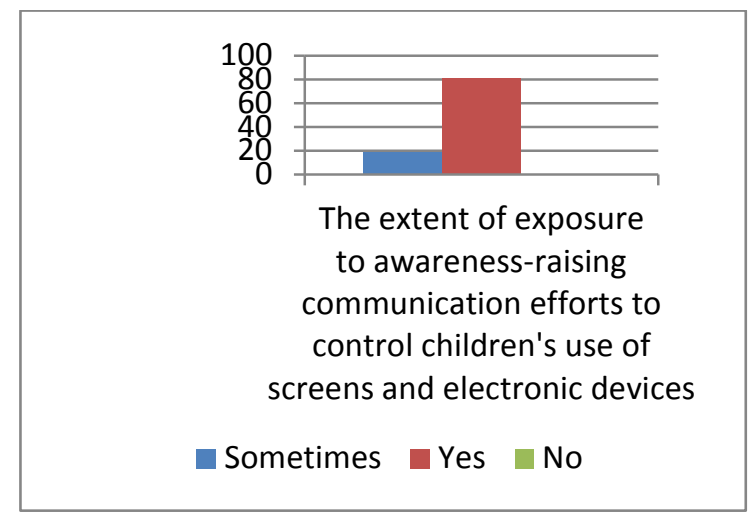

The above graph shows the high percentage of those who have been exposed to awarenessraising communication efforts and efforts to control and rationalize their children's use of electronic devices and screens, $(81 \%)$ of the sample indicated that they were exposed to these efforts and communication messages are continuing, in addition to the $(19 \%)$ of the sample who stated that they are sometimes exposed to such messages from different communication sources, with the absence of the percentage of those who have not been exposed to any communication efforts that carry awareness messages concerning the control and rationalization of children's use of electronic devices and screens, this reflects the great effectiveness of awareness activities, whatever their source or type, in reaching the 
target audience and achieving highly targeted results.

Table (1): shows the distribution of the sample of the study in terms of sources of communication efforts and awareness messages that have been exposed

\begin{tabular}{|c|c|c|}
\hline \multirow[t]{2}{*}{ Sources } & \multicolumn{2}{|c|}{$\begin{array}{c}\text { Total } \\
\text { sample }\end{array}$} \\
\hline & $\mathrm{N}$ & $\%$ \\
\hline $\begin{array}{l}\text { Internet and phone applications } \\
\text { such as (websites, social } \\
\text { networking platforms, chat and } \\
\text { communication programs and } \\
\text { applications) }\end{array}$ & 289 & 64.2 \\
\hline $\begin{array}{l}\text { Traditional media (television, } \\
\text { radio, newspapers). }\end{array}$ & 221 & 49.1 \\
\hline $\begin{array}{l}\text { Direct communication efforts of } \\
\text { interested parties and } \\
\text { institutions. }\end{array}$ & 116 & 25.8 \\
\hline $\begin{array}{l}\text { Personal advice from } \\
\text { knowledgeable and experienced } \\
\text { people. }\end{array}$ & 235 & 52.2 \\
\hline 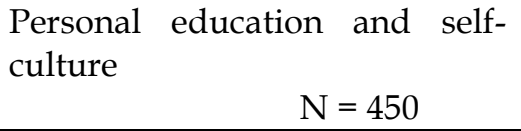 & 213 & 47.3 \\
\hline
\end{tabular}

It is clear from the previous table the multiplicity of sources from which the sample of the study obtained their information about the controls on the use of electronic devices and screens for children, where communication messages outperformed the new internet-based media, and phone applications by $(64.2 \%)$, this reflects the effectiveness of reliance on these means and the study sample's reliance on digital media as an important source of education, then were the personal advice of the family, the family, and friends of business, specialists and knowledgeable people by $(52.3 \%)$, which is a high percentage reflects the importance of personal communication and retain its importance despite the development of digital means of communication, this result may also emphasize the value of social relations and personal networks in Arab societies, it was also noted that the high rate of dependence on education and personal education, which was associated with the high percentage of education for the sample as appeared in the results of the analysis of the basic data of the respondents.
Figure (2): shows the awareness of the sample of the risk of irrational use of electronic devices and screens

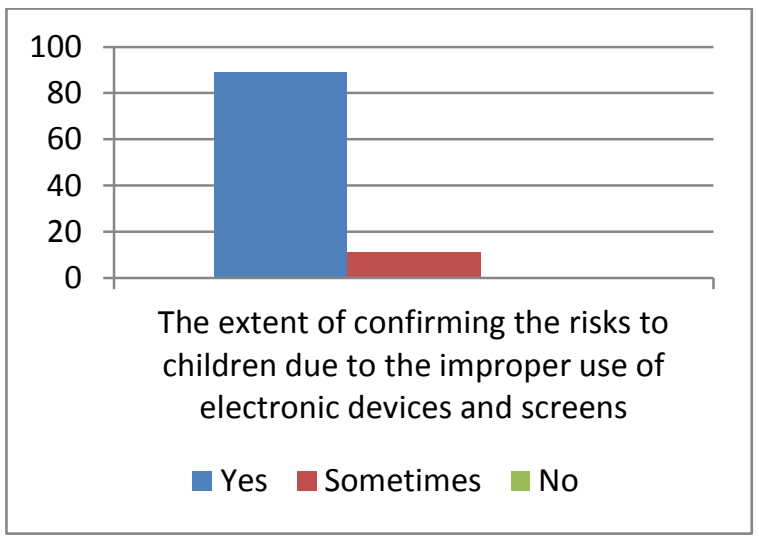

The above chart shows that $(88.9 \%)$ of the sample are aware of the risk of irrational use of electronic devices and screens, especially on children, while $(11.1 \%)$ believe that the risk is unlikely to occur, where they explained in the discussions with the researcher that the side effects may be exposed to the child with heavy use only, they pointed out that the damage is relative to the child and his psychological and physical readiness, however, they believe that there are potential risks, while none of the sample believed that electronic devices and screens had no risk to children, this is due to the high rate of education among the study sample, perhaps the absence of the percentage of uneducated people from the sample, which indicates the awareness of parents of the risk of irrational use of devices and electronic screens.

Figure (3): Parents' awareness of the procedures and controls, or health instructions regarding the exposure of their children to these devices

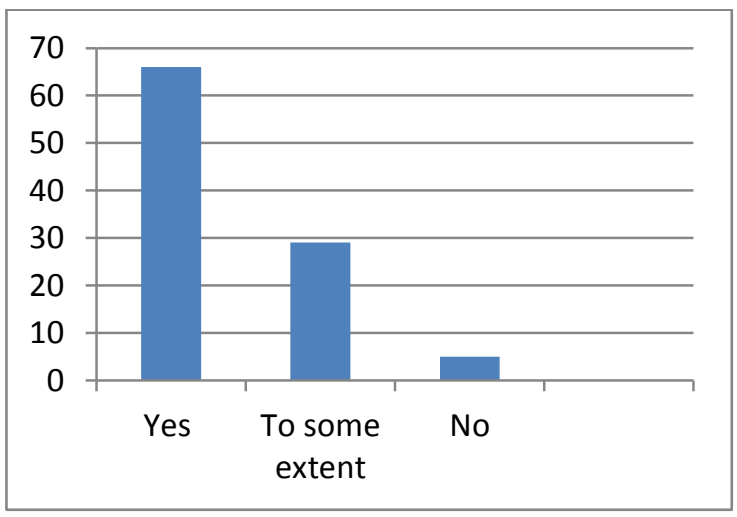

The above chart shows that the awareness of the instructions and controls of children using screens and electronic devices among their parents is fully increased by $66 \%$, and in an 
incomplete manner by $29 \%$, this may be due to the multiplicity of sources of guidance, and the multiplicity of media that carried and delivered those controls as shown in Table (1), also, the percentage of those who are not familiar with the rules of rational use of these devices decreased to $5 \%$, as they represent a small percentage that understands the need for rationalization without awareness of the details of instructions and hours of use for each age group and prevention for those under two years of age, these results may be explained, as noted above, by the high rate of education among the sample and its distinctive presence in the region and a developed country in the communication domains and make special efforts in the areas of awareness.

Figure (4): The extent of the parents' application of the procedures and health controls for the exposure of their children to these devices

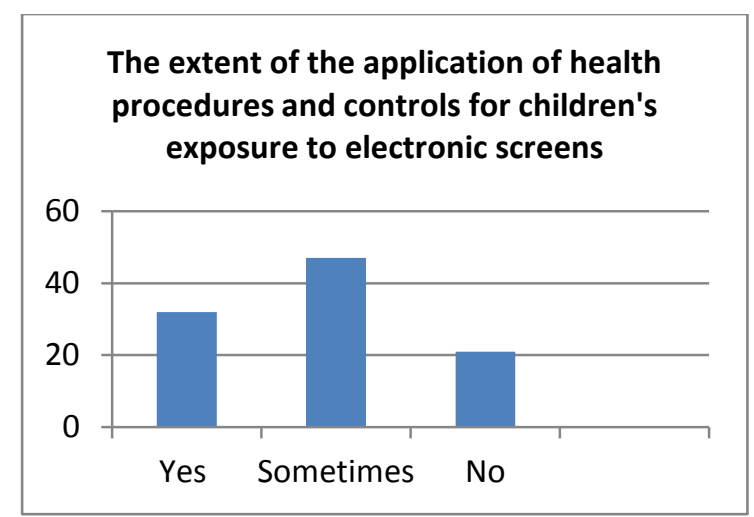

The above chart shows that the percentage of those who do not implement the procedures and regulations to rationalize the use of electronic screens in general is up by $21 \%$, this is an indication of the ineffectiveness of awareness-raising efforts in convincing all target audiences of the need to implement procedures and controls for the children using of these devices.

When comparing the results of what the previous chart indicates, with the results in graphs (1), (2) and (3), the following is illustrated, that parents are exposed to awareness messages about the danger of their children using these devices (see diagram 1) with different sources of educational messages (see Table 1), this has resulted in a high awareness of the seriousness of these devices with a high rate that may be very satisfactory to any educational or health institution working to transmit awareness messages, this has resulted in a heightened awareness among parents of the rational use of children for these devices, however, the researcher found a gap of $(21 \%)$ of the sample of the study aware of the seriousness of children use of these devices and yet they do not apply any procedures or controls to rationalize the use of these devices by their children, this indicates that the communication activities related to raising the educational awareness of the parents have reached the target group in one way or another at very good rates, these communication efforts have contributed to raising awareness of the target audience, but the effectiveness of these communication efforts has not achieved its full aim in changing the behavior of the target audience, responding to the calls of communication efforts to take practical steps towards establishing and applying controls to rationalize the use of screens and electronic devices by children; this has been shown again that $(47 \%)$ of the sample sometimes adhere to the application of controls and sometimes not, while $(32 \%)$ of the public adhered to health regulations and specialist instructions, this refers to achieving the effectiveness of communication efforts and achieving the full objectives set to draw the attention of the target audience and raise their levels of awareness and to achieve the response and change in their educational behaviors, for a third of the sample only, while nearly twothirds of the audience remain, communication efforts as effectively as the full mark, despite their progress, have not progressed.

Third: Hypothesis testing results.

Table (2): differences between parents with regard to the extent of awareness of the seriousness of their children use of screens and electronic devices

\begin{tabular}{lccccc}
\hline Groups & Mean & $\begin{array}{c}\text { Standard } \\
\text { deviation }\end{array}$ & $\begin{array}{c}\text { "T" } \\
\text { value }\end{array}$ & Moral & Sig \\
\hline Fathers & 1.517 & 0.655 & -1.301 & 0.194 & $\begin{array}{c}\text { Not } \\
\text { significant }\end{array}$ \\
\hline Mothers & $\mathbf{1 . 5 9 9}$ & $\mathbf{0 . 6 7 2}$ & & &
\end{tabular}

From the results shown in this table, there are statistically significant differences between parents regarding their awareness of the seriousness of their children using screens and electronic devices, where the differences were assimilated in arithmetic differences that were not significant. 
Table (3): differences between parents regarding the extent of their adherence to the controls used by their children for screens and electronic devices

\begin{tabular}{lccccc}
\hline Groups & Mean & $\begin{array}{c}\text { Standard } \\
\text { deviation }\end{array}$ & $\begin{array}{c}\text { value } \\
\text { paral }\end{array}$ & Mig \\
\hline parents 2.492 & 0.632 & 2.213 & 0.027 & Significant \\
\hline Mothers 2.356 & $\mathbf{0 . 6 6 4}$ & & & \\
\hline Degree of freedom $=448$ & & &
\end{tabular}

It is clear from the previous table that there are statistically significant differences between parents by $(2.213)$ and significant $=(0.027)$ in favor of the first group, which was less willing to abandon health controls and instructions for controlling the children's usage of screens and electronic devices, and that was the highest mean of (2.492), while the second group (females) had the lowest mean of (2.356), this means that this group is more willing to give up controls to achieve a goal, which may be commensurate with the emotional nature of women and offset the materialistic nature of men.

Through the application of the Pearson correlation coefficient to detect the existence of a significant relationship between the follow-up of media and social media followup, and the parents' perception of the danger of children using screens and electronic devices, the following results were shown:

- First: There is a statistically significant correlation between the follow-up of traditional media variable (newspapers, radio, TV) and parents' perception of the danger of children using screens and electronic devices, where the value of $R$ was (0.126) and a significant amount of (0.007) which is significant at the level of significance (0.01) and a mean of (2.222), from this we can say that the respondents' answers differed or influenced by the follow-up of the media.

- Second: There is a statistically significant correlation between social media followup, and the parents' perception of the danger of children using screens and electronic devices, where the value of $R$ reached (0.204) and a significant amount of $(0.000)$ which is significant at the level of significance (0.01) and a mean of (2.633), this makes it clear that the vision of parents is positively affected by the danger of their children using screens and electronic devices without rationalization.

\section{Results}

1. Effectiveness of communication efforts of all kinds in reaching the target audience (parents) and to identify the danger of children using screens and electronic devices in an uncontrolled or rational manner, as a result, parents' awareness of the risks of uncontrolled and rational use of screens and electronic devices increased by $88.9 \%$.

2. Digital media (web-based) and social media platforms are effective in educating parents about the dangers of uncontrolled use of screens and electronic devices by $64.2 \%$, this is followed by personal communication with parents, family and specialists $(52.3 \%)$, then traditional media (radio, television, newspapers) and finally the Communicative awareness efforts of institutions and specialized agencies interested in that in general, health care and education in particular, by $25.8 \%$, and Care and health awareness in particular, by $25.8 \%$, education and self-education of the sample also contributed to raising awareness by $47.3 \%$, which was reflected in the total drop in the percentage of those who do not have enough information on the controls of the rational use of devices and electronic screens to $5 \%$.

3. It was found that the effectiveness of the various communication efforts to raise awareness about the danger of children using screens and electronic devices did not achieve its full aim in reaching its ultimate goal of changing the behavior of the target audience (parents) or achieving the response regarding the need to take and apply the instructions for the rational use of screens and electronic devices by their children, it was found that $21 \%$ of parents do not implement any procedures to rationalize the use of their children for these devices, this high percentage shows that parents' awareness of the danger of their children using these devices in an uncontrolled manner may not be sufficient to apply rules and procedures to achieve discipline of employment in a way that ensures the health of children.

4. The results of the hypothesis tests show the following:

a. There are no statistically significant differences between parents regarding the 
extent of awareness of the seriousness of their children using screens and electronic devices.

b. Mothers were found to be less adherent to the regulations on child use of electronic devices than parents.

c. There is a statistically significant correlation between the variable of traditional media follow-up (newspapers, radio, TV) and parents' perception of the risks of children using screens and electronic devices.

d. There is a statistically significant correlation between social media follow-up and parents' perception of the risks of children using screens and electronic devices.

\section{References}

- Abu Taleb, B. (2017). The American Academy of Pediatrics sets the time to use smart devices. Retrieved from masrawy: http://www.masrawy.com

- Adly, A. and Ahmed, Z. (1993). Statistical Method and its Uses in Public Opinion and Media Research, Cairo: Arab Thought House.

- Al-Saadi, F. (2018). Child and electronic games via new media, Amman: Gulf House.

- Bar-on, M., Broughton, D. , Buttross, S., Corrigan, S., Gedissman, A., Rosario Gonzalez de Rivas, M., et al. (2001). Children, adolescents, and television. Pediatrics, 107(2), 423-426

- Cain, N., \& Gradisar, M. (2010). Electronic media use and sleep in school-aged children and adolescents: A review. Sleep Medicine, 11(8), 735-742.

- Harwood, J. Dooley, J, Scott, A. and Joiner, R. (2014). Constantly connected-The effects of smart-devices on mental health, Computers in Human Behavior, 34 ; 267272

- Jaafreh, H. (2008). Motor disorders in children, Osama Publishing \& Distribution House, Amman, Jordan

- Hysing, M. Pallesen, S. Stormark, K. Jakobsen, R. Lundervold, A. Sivertsen, B.
(2015). Sleep and use of electronic devices in adolescence: results from a large population-based study. BMJ open, 5(1), e006748.

- Jaafreh, H. (2008). For motor disorders in children, Osama Publishing \& Distribution House, Amman, Jordan

- Misaa almazme (2013). Retrieved from emaratalyoum:

https://www.emaratalyoum.com

- Olivia solon (2016). smartphones won't make your kids dumb- we think. Scientific American. Retrieved from https://www.scientificamerican.com/arti cle/smartphones-won-t-make-your-kidsdumb-we-think/

- Hysing, M., Pallesen, S., Stormark, K. M., Jakobsen, R., Lundervold, A. J., \& Sivertsen, B. (2015). Sleep and use of electronic devices in adolescence: results from a large population-based study. BMJ open, 5(1), e006748.

- Hatem Ja'afreh, Motor Disorders in Children, First Edition (Amman: Osama Publishing and Distribution, 2008), p. 109.

- Basma Abu Taleb, American Academy of Pediatrics, determines the time to use smart devices. Retrieved from masrawy: http://www.masrawy.com. Date (December 20, 2017).

- Cain, N., \& Gradisar, M. (2010)., op.cit..

- M Hysing ‘Pallesen, S. et, all., op.cit.

- Zarkona, Mbarka., Child and technology between uses and influences (Algeria, University of Mohamed Boudiaf Balmcilh, Faculty of Humanities and Social Sciences: 2018).

- Mashael bint Mohammed Saqabi,. Challenges posed by electronic devices to dialogue and communication with children, (2015).

- misaa almazme, emaratalyoum: https:// www.emaratalyoum.com, 28 June, 2013

- Atef Adly and Zaki Ahmed, Statistical Method and its Uses in Public Opinion and Media Research. Cairo: Dar Al Fikr Al Arabi, 1993. 